\title{
Nursing Associate: Our chance to influence
}

It is well recognised that currently, there is a global shortage of registered nurses, indicating a significant increase in the numbers of unregistered support workers relative to registered nurses (RN) (Griffiths et al 2016). Additionally, with the increasing ageing workforce, the shortages set to continue (Jackson 2008, Graham \& Duffield 2007). In particular, staff levels of registered nurses are associated with patient mortality, with a higher level of RNs associated with lower mortality and enhanced quality of care (Aiken et al 2014). So, it seems timely to consider a higher level assistant role, educated to a level immediately below the RN level and building on the Care Certificate of the Healthcare Assistant (HCA) advocated by Cavendish (2013) but with a view to supporting a career progression route to RN. The new role of Nursing Associate (the name has yet to be agreed), was recommended by the government in England $17^{\text {th }}$ December 2015 and at the end of January 2016 went out to consultation (HEE 2016).

However, we have been here before. The introduction of the mandatory Diploma level preparation for RNs (Project 2000) in the late 1980s, aimed to facilitate one entry level to the register. However, in the process, marginalised those existing enrolled nurses, requiring them to convert to first level registration (Dowswell et al 1998). It is true that enrolled nurses had little opportunity to progress in their career, nor any recognised education pathway, even before Project 2000 . Once their preparation was withdrawn in the 1990s, unless they wished to remain in their role, they were required to retrain to convert to RN. Now, with the move to an all-graduate intake for RN, there seems more of a need to widen the entry gate. We need to learn from the past, value our nursing workforce and build a career trajectory that will encourage progression at all levels.

So, what of this new role of Nursing Associate? The consultation makes clear that they should be educated to Foundation degree level, and aligned to the outcomes of the Registered Nurse "underpinned by nationally accredited and transportable skills" (HEE 2016, p112) in an apprenticeship-style delivery model. So, the introduction of a new type of nursing support worker with a higher skillset than HCA and with the underpinning values base is planned to strengthen the nursing contribution to person-centred care, across the myriad of care settings. As a profession, we have a real opportunity to advise the government as to how we can best value our assistant workforce and ultimately, enhance the wider nursing team by responding to this consultation. This has been your opportunity to influence the future.

One of the major questions we ought to be considering, is whether this role should be regulated (at cost to the individual). As one of only three European countries that do not currently regulate its assistant workforce, there needs to be consistent standards of education, training and quality enhancement processes in place for regulation to be considered. Indeed, employers are already introducing the new Care Certificate (or its equivalent) within a framework that will encourage progression to RN (Willis 2015). However, in his review, Willis (2015) identified that HCAs wished to feel part of a wider career structure and not merely progression to RN, so the introduction of a Nursing Associate would tailor a distinct preparation purely for those with an interest in nursing. Nevertheless, the workforce already has the Assistant Practitioner role (Agenda for Change, Band 4) which Willis (2015) recognised can act as a bridge between RNs and the HCA. With HCAs spending more time than RNs in direct patient care (Cavendish 2013), investing in a 
bespoke and higher level nursing assistant role has the potential to raise morale, lower staff turnover and promote a marked improvement in the quality of care (Willis 2015).

So, what is the difference between Assistant Practitioner and Nursing Associate? It seems that, unlike the generic title of Assistant Practitioner which spans across professional groups, the new role of Nursing Associate will entirely focus on assisting the RN to become an integral part of the wider nursing team. The Nursing Associate will be equipped with a sound and specific knowledge base and expand the delivery of care by nursing teams as well as offer the opportunity, through an apprenticeship model of delivery to progress to RN in a well orchestrated career plan, with clear step-on and step-off points along the way (HEE 2016). As HEE $(2016, p 8)$ recommends, the plan is to "skill, reskill and upskill all the roles which contribute to improving the health and care of the population".

So, if we are to think strategically and creatively about addressing the nursing shortage and look to the wider nursing workforce to build a well planned career pathway from all levels of assistant through to RN and beyond, then the role of the Nursing Associate will have much to offer. Nevertheless, we must avoid the mistakes of the past. To prevent their marginalisation as the Enrolled nurse experienced, collectively we have a role to play in influencing the way forward. We ought to be listening to our colleagues and representing their views and the interests of the wider team to promote high standards of care. I hope you have sent in your response, otherwise others will decide for us.

\section{References}

Aiken, L.H., Sloane, D.M., Bruyneel, L., Van den Heede K; Griffiths P; Busse R; Diomidous M; Kinnunen J; Kózka M; Lesaffre E; McHugh MD; Moreno-Casbas MT; Rafferty AM; Schwendimann R; Scott PA; Tishelman C; van Achterberg T; Sermeus W; RN4CAST consortium, (2014) Nurse staffing and education and hospital mortality in nine European countries: a retrospective observational study. Lancet, 383, 1824-30.

Cavendish, C. (2013) The Cavendish Review: An independent review into healthcare assistants and support workers in the NHS and social care settings. July, Accessed on 26.2.16 at https://www.gov.uk/government/uploads/system/uploads/attachment data/file/236212/Caven dish Review.pdf

Dowswell, T. Hewison, J. \& Miller, B. (1998) Enrolled nurse conversion: trapped into training, Journal of Advanced Nursing, 28(3), 540 - 547.

Graham, E.M. \& Duffield, C. (2010) An ageing nursing workforce. Australian Health Review, 34, 44-48.

Griffiths, P., Ball, J., Murrell, T., Jones, S. \& Rafferty A.M. (2016) Registered nurse, healthcare support worker, medical staffing levels and mortality in English hospital trusts: a cross-sectional study. BMJ Open, Accessed on 26.2.16 at http://bmjopen.bmj.com/ February 16.

Health Education England (2016) Building capacity to care and capability to treat - a new team member for health and social care: Consultation. Accessed on 26.2.16 from 
http://www.hee.nhs.uk/our-work/developing-our-workforce/nursing/have-your-say-newsupport-role-nursing

Jackson D. (2008) (Editorial) The ageing nursing workforce: how can we avoid a retirement brain drain? Journal of Clinical Nursing, 17, 2949 - 2950.

Willis (2015) Raising the Bar: Shape of Caring: A Review of the Future Education and Training of Registered Nurses and Care Assistants. March, Health Education England, Accessed on 5.1.16 at https://hee.nhs.uk/printpdf/our-work/developing-ourworkforce/nursing/shape-caring-review

Professor Elizabeth Rosser, Deputy Dean Education and Professional Practice, Bournemouth University 